Acta Agroph., 2019, 26(3), 57-64

doi: $10.31545 /$ aagr/115217

\title{
EFFECT OF WEATHER CONDITIONS ON THE CONTENT OF SUGARS IN PLANTS OF EUROPEAN MAIZE CULTIVARS GROWN FOR SILAGE
}

\author{
Barbara Gąsiorowska@, Anna Ptaza®, Emilia Rzążewska®, Michat Waranica® \\ Institute of Agriculture and Horticulture, Department of Bioengineering and Animal Husbandry \\ Siedlce University of Natural Sciences and Humanities \\ Bolesława Prusa 14, 08-110 Siedlce, Poland \\ e-mail: anna.plaza@uph.edu.pl
}

\begin{abstract}
A bstract. The paper presents the results of a study from the years 2009-2011, aimed at the determination of the effect of the temperature and rainfall conditions of central-east Poland on the content of dry matter and sugars in plants of selected European maize cultivars grown for silage. Two factors were analysed in the experiment: A. Time of harvest of maize green forage: I - stage of panicle formation ( $75 \%$ of plants in that stage of growth), II - stage of milky ripeness (after three weeks), III - stage of waxy ripeness (after another three weeks), and B. Cultivars with differing duration of the period of vegetation: Pyroxenia - very early cultivar, FAO 130, Codimi - early cultivar, FAO 200, Moschus - early cultivar, FAO 220, Alombo - early cultivar, FAO 230, Celive - medium early cultivar, FAO 245. The following parameters were assayed in the plant material: content of dry matter, starch, soluble sugars, and reducing sugars. The results obtained allow to state that the weather conditions in the years of the experiment significantly differentiated the content of sugars in maize plants. Green forage of maize cultivars Codimi, Pyroxenia and Alombo harvested in the stage of waxy ripeness in 2010, a year with the highest precipitation total, was characterised by the highest content of starch.

Ke y w ord s: maize, cultivars, time of harvest, content of sugars, weather conditions
\end{abstract}

\section{INTRODUCTION}

Weather conditions during the vegetation of maize have a strong impact on the yield and on the chemical composition of green forage (Sowiński and LiszkaPodkowa 2008). Maize, as opposed to other crop plants harvested for silage, accumulates nutrients until the moment of attaining full ripeness. From the stage of panicle formation, with the progress of the period of vegetation the energy value of maize dry matter increases. Highly important with respect to maize harvest is the degree of ripeness of grain which, together with the cob, constitutes the main part of the plant that determines the amount and quality of the harvested product 
(Sulewska et al. 2011). Towards the end of the period of vegetation there takes place intensive accumulation of hydrocarbons, mainly starch, causing a change in the structure of the green forage. The contribution of grain increases, with a proportional decrease in the participation of stems, leaves and cob cores, and thus the nutritive value of the green forage increases (Podkówka et al. 2015).

The nutritive value of green forage from maize plants is also significantly affected by the choice of cultivars. After the accession of Poland to the European Union structures, new cultivars can be selected for research from the Common Catalogue of Varieties of Agricultural Plant Species (CCA), of the "stay green" type, the characteristic feature of which is the ripening of grain while maintaining the green form of the plant (Hertman et al. 2000). Therefore, the appearance on the market of new cultivars from the Common Catalogue (CCA) provides a stimulus for undertaking research on the determination of their suitability for cultivation in our country.

The objective of the study presented herein was to determine the effect of the temperature and rainfall conditions on central-east Poland on the content of dry matter and sugars in plants of selected European maize cultivars grown for silage.

\section{MATERIAL AND METHOD}

The field experiment was conducted in the years 2009-2011, at a private farm situated in the locality Kowiesy near Siedlce $\left(52^{\circ} 03^{\prime} 39^{\prime \prime} \mathrm{N}, 22^{\circ} 33^{\prime} 80^{\prime \prime} \mathrm{E}\right)$. The field experiment was conducted on a sandy grey-brown podzolic soil, with slightly acidic reaction, and medium levels of available phosphorus, potassium and magnesium. Humus content was $1.28 \%$. The experiment was set up in the split-plot design, with three replicates. Two factors were analysed in the experiment: A. Time of harvest of maize green forage: I - stage of panicle formation $(75 \%$ of plants in that stage of growth), II - stage of milky ripeness (after three weeks), III - stage of waxy ripeness (after another three weeks), and B. Cultivars with differing duration of the period of vegetation: Pyroxenia - very early cultivar, FAO 130 (Zeainvent Trnava s.r.o.), Codimi - early cultivar, FAO 200 (Codisem), Moschus - early cultivar, FAO 220 (Freiherr von Moreau Saatzucht GmbH), Alombo - medium early cultivar, FAO 230 (Freiherr von Moreau Saatzucht GmbH), Celive - medium early cultivar, FAO 245 (Cezea).

Plant density was $10 \mathrm{pcs} \mathrm{m}^{-2}$, and the applied sowing norm was based on the results obtained in an earlier study by Sulewska (2001). Maize was cultivated in monoculture. In autumn, cattle manure was applied in the dose of $30 \mathrm{tha}^{-1}$. In spring, phosphorus-potassium fertilisation was applied, at doses adapted to the soil content of available components, i.e. $60 \mathrm{~kg} \mathrm{P} \mathrm{ha}^{-1}$ and $90 \mathrm{~kg} \mathrm{~K} \mathrm{ha}^{-1}$. Nitrogen fertilisation was also applied in spring, prior to maize sowing, in the dose of $92 \mathrm{~kg} \mathrm{~N} \mathrm{ha}^{-1}$. The additional dose of nitrogen was supplemented through the application of a mineral 
fertiliser in the form of Polisfoska 6. Grain of the studied maize cultivars was sown in the $3^{\text {rd }}$ decade of April, in accordance with the second experimental factor. Harvest of plants for green forage was conducted on three dates, in accordance with the first experimental factor. At the harvest times, samples of plant material were collected from each plot, for the determination of the content of dry matter, starch, soluble sugars and reducing sugars, with the use of near-infrared spectroscopy NIRS, using an NIRFex N-500 apparatus. The results were processed statistically, and for each of the analysed traits analysis of variance was performed, suitable for a two-factor experiment set up in the split-plot design. For detailed comparison of mean values, the least significant differences LSD were calculated on the basis of Tukey's test, at significance level of $\alpha_{0.05}$.

The temperature and rainfall conditions in the years of the experiment are presented in Table 1. The year 2010 was characterised by the highest average air temperature and the highest precipitation total. In 2009 the precipitation total was lower, though still higher that the multi-year average, but the mean air temperature was lower than the multi-year average. In 2011 the lowest precipitation total was noted, lower than the multi-year average, and the mean air temperature oscillated around the level of the multi-year average.

Table 1. Temperature and rainfall conditions during maize vegetation according to the Meteorological Station at RSD Zawady

\begin{tabular}{lrrrrrrr}
\hline \multirow{2}{*}{ Year } & \multicolumn{9}{c}{ Month } & & Mean/total \\
\cline { 2 - 8 } & IV & \multicolumn{1}{c}{ V } & VI & VII & VIII & IX & Air temperature, ${ }^{\circ} \mathrm{C}$ \\
2009 & 10.3 & 12.9 & 15.7 & 19.4 & 17.7 & 14.6 & 15.1 \\
2010 & 8.9 & 14.0 & 17.4 & 21.6 & 19.8 & 11.8 & 15.6 \\
2011 & 10.1 & 13.4 & 18.1 & 18.3 & 18.0 & 14.4 & 15.4 \\
Multi-year mean 1990-2008 & 8.3 & 14.1 & 17.5 & 19.8 & 18.9 & 13.1 & 15.3 \\
& \multicolumn{3}{c}{ Precipitation total, mm } & & & \\
2009 & 8.1 & 68.9 & 145.2 & 26.4 & 80.9 & 24.9 & 354.4 \\
2010 & 10.7 & 93.2 & 62.6 & 77.0 & 106.3 & 109.9 & 459.7 \\
2011 & 31.0 & 36.1 & 39.1 & 120.2 & 18.6 & 12.0 & 257.0 \\
Multi-year mean 1990-2008 & 35.6 & 49.3 & 47.5 & 63.4 & 54.2 & 47.8 & 297.8 \\
\hline
\end{tabular}

\section{RESULTS AND DISCUSSION}

Dry matter content in maize plants was significantly differentiated by the weather conditions during the vegetation period and their interaction with the analysed experimental factors (Tab. 2). The highest dry matter content was noted in maize plants harvested in 2010, significantly lower in 2011, and the lowest in plants harvested in 2009. Also studies by Hopkins (2003) and by Farre and Faci (2006) indicate a differentiation in the chemical composition of maize plants cultivated in variable weather conditions. Our study demonstrated an interaction of the temperature and rainfall conditions with the analysed factors on the content of dry matter in 
maize plants. The highest dry matter content was noted and in all the years of the study, with the exception of cv. Celive harvested in 2011, in the phase of waxy ripeness. Also Tolera et al. (1998), Yuxiang et al. (2007), Magalhäes et al. (2015) and Swanckaert et al. (2016) demonstrated the lowest dry matter content in plants of maize cv. Celive, characterised by the longest period of vegetation. In the presented study a high dry matter content was also characteristic of green forage of maize cv. Codimi harvested in 2011, and of all maize cultivars harvested in 2010 in the phase of milky ripeness. The lowest dry matter content was characteristic of all maize cultivars harvested in 2011 in the earliest stage of development, i.e. in the stage of panicle formation. This is in conformance with the results obtained by Tolera et al. (1999), Sulewska (2001), Schittenhelm (2008) and Podkówka et al. (2015).

Table 2. Dry matter content in maize plants, $\mathrm{g} \cdot \mathrm{kg}^{-1}$

\begin{tabular}{llccc}
\hline \multirow{2}{*}{ Time of harvest } & \multicolumn{1}{c}{ Cultivar } & 2009 & 2010 & 2011 \\
\cline { 3 - 5 } I & Pyroxenia & 142.5 & 162.8 & 121.0 \\
& Codimi & 137.6 & 149.0 & 125.0 \\
& Moschus & 128.8 & 137.3 & 127.9 \\
& Alombo & 135.0 & 135.7 & 131.5 \\
II & Celive & 127.1 & 148.2 & 132.1 \\
& Pyroxenia & 220.3 & 295.9 & 213.9 \\
& Codimi & 209.1 & 301.6 & 231.6 \\
& Moschus & 185.8 & 321.7 & 209.1 \\
& Alombo & 188.4 & 264.2 & 195.6 \\
III & Celive & 185.4 & 262.6 & 206.7 \\
& Pyroxenia & 311.2 & 350.5 & 422.7 \\
& Codimi & 317.5 & 361.4 & 391.5 \\
& Moschus & 275.2 & 338.9 & 376.8 \\
& Alombo & 284.1 & 365.1 & 375.6 \\
Mean & Celive & 267.8 & 354.2 & 353.0 \\
\hline
\end{tabular}

$\mathrm{LSD}_{0.05}$ for years -20.1 , interaction: years $\times$ harvest times $\times$ cultivars -51.9 .

Statistical analysis revealed a significant effect of the temperature and rainfall conditions and of their interaction with the analysed experimental factors on the content of starch in maize plants (Tab. 3). The highest content of starch was noted in maize plants harvested in 2010, significantly lower in 2011, and the lowest in plants harvested in 2009. Also a study by Farre and Faci (2006) indicated a differentiation in the chemical composition of green forage of maize cultivated in varied temperature-rainfall conditions. In the presented study, the highest starch content was noted in plants of maize cultivars Pyroxenia, Codimi, Moschus, Alombo and Celive harvested in the phase of waxy ripeness in 2010. A high concentration of starch was also characteristic of all maize cultivars harvested in 2011 and 2009, with the exception of $\mathrm{cv}$. Alombo in the phase of waxy ripeness. The results obtained find support in reports by other authors (Tolera et al. 1998, Stejskalova et al. 2013, Magalhäes et al. 2015, Nawab and Anju 2017). In the presented experiment 
a high content of starch was noted in maize plants cv. Pyroxenia harvested in 2010 in an earlier phase of development, i.e. in the phase of milky ripeness. Also Tolera et al. (1999), Strzetelski et al. (2001) and Szempliński et al. (2009) indicate a higher content of starch in dry matter of plants of maize cultivars with a shorter vegetation period, in years with optimum distribution of rainfalls and air temperatures during the vegetation period. In our study, the lowest content of starch was noted in plants of all the maize cultivars harvested in the stage of panicle formation in 2009. This results from the fact that in the earlier stages of development maize plants are characterised by a higher content of soluble sugars and reducing sugars, and a lower content of starch (Michalski et al. 2002, Filya 2004).

Table 3. Starch content in maize plants, $\mathrm{g} \mathrm{kg}^{-1} \mathrm{DM}$

\begin{tabular}{llrrr}
\hline \multirow{2}{*}{ Time of harvest } & \multicolumn{1}{c}{ Cultivar } & 2009 & 2010 & 2011 \\
\cline { 3 - 5 } I & Pyroxenia & 15.8 & 59.6 & 20.5 \\
& Codimi & 16.2 & 87.7 & 97.1 \\
& Moschus & 23.5 & 76.4 & 52.2 \\
& Alombo & 19.9 & 74.8 & 27.1 \\
II & Celive & 12.5 & 68.0 & 74.5 \\
& Pyroxenia & 187.1 & 451.4 & 202.0 \\
& Codimi & 85.4 & 301.9 & 209.0 \\
& Moschus & 92.9 & 298.9 & 177.5 \\
& Alombo & 71.6 & 240.0 & 165.2 \\
III & Celive & 52.5 & 288.8 & 188.3 \\
& Pyroxenia & 323.9 & 479.4 & 401.3 \\
& Codimi & 307.6 & 490.1 & 384.3 \\
& Moschus & 256.1 & 420.8 & 369.4 \\
& Alombo & 238.1 & 480.4 & 349.8 \\
Mean & Celive & 263.1 & 469.3 & 347.2 \\
\hline
\end{tabular}

$\mathrm{LSD}_{0.05}$ for years -26.2 , interaction: years $\times$ harvest times $\times$ cultivars -83.1 .

The content of soluble sugars and reducing sugars in maize plants was significantly differentiated by the weather conditions and their interactions with the analysed factors (Tabs 4 and 5). The highest content of soluble sugars was noted in maize plants harvested in 2009, significantly lower in 2011, and the lowest in 2010. The chemical composition of maize green forage is determined in $30 \%$ by the weather conditions (Ptaszyński and Sulewska 2008). In our study, the highest concentration of soluble sugars and reducing sugars was noted in plants of all of the analysed maize cultivars harvested in the stage of milky ripeness in 2009. A high content of soluble sugars was noted also in plants of cv. Pyroxenia harvested in the stage of panicle formation in 2009, and of reducing sugars - in plants of the same maize cultivar harvested in the same development stage in all the years of the study. The above correlation is supported also in studies by Lynch et al. (2012) and by Magalhäes et al. (2015). In the presented experiment, the lowest content of reducing sugars was noted in plants of all maize cultivars harvested in the phase of waxy 
ripeness in 2010. This should be attributed to the fact that a delay of the harvest of maize green forage till the phase of waxy ripeness causes a decrease in the content of soluble sugars and reducing sugars in plants, and an increase in the content of starch, especially in years with a favourable course of the weather conditions in the period of vegetation. Harvesting maize plants in the stage of waxy ripeness ensures the highest content of starch, which guarantees good quality of silage. Among the analysed maize cultivars, cv. Pyroxenia was characterised by the highest content of starch, in all the years of the study.

Table 4. Content of soluble sugars in maize plants, $\mathrm{g} \mathrm{kg}^{-1} \mathrm{DM}$

\begin{tabular}{llrll}
\hline \multirow{2}{*}{ Time of harvest } & \multicolumn{1}{c}{ Cultivar } & 2009 & 2010 & 2011 \\
\cline { 3 - 5 } I & Pyroxenia & 132.3 & 73.0 & 36.8 \\
& Codimi & 87.9 & 29.4 & 43.4 \\
& Moschus & 86.9 & 30.4 & 43.3 \\
& Alombo & 86.4 & 36.3 & 29.1 \\
II & Celive & 76.7 & 41.5 & 50.7 \\
& Pyroxenia & 114.1 & 26.3 & 75.8 \\
& Codimi & 136.7 & 41.0 & 57.8 \\
& Moschus & 126.0 & 50.5 & 67.2 \\
& Alombo & 123.8 & 63.2 & 70.0 \\
III & Celive & 122.1 & 56.5 & 68.8 \\
& Pyroxenia & 61.9 & 14.3 & 25.3 \\
& Codimi & 59.2 & 15.0 & 42.8 \\
& Moschus & 84.5 & 25.4 & 40.0 \\
& Alombo & 92.1 & 15.8 & 58.3 \\
Mean & Celive & 72.5 & 16.0 & 57.1 \\
\hline
\end{tabular}

$\mathrm{LSD}_{0.05}$ for years -9.7 , interaction: years $\times$ harvest times $\times$ cultivars -33.6 .

Table 5. Content of reducing sugars in maize plants, $\mathrm{g} \mathrm{kg}^{-1} \mathrm{DM}$

\begin{tabular}{llrrr}
\hline \multirow{2}{*}{ Time of harvest } & \multicolumn{1}{c}{ Cultivar } & 2009 & Year \\
\cline { 2 - 5 } I & Pyroxenia & 73.4 & 2010 & 2011 \\
& Codimi & 59.4 & 26.4 & 39.9 \\
& Moschus & 56.6 & 26.1 & 45.1 \\
& Alombo & 56.4 & 30.1 & 44.7 \\
II & Celive & 53.5 & 32.3 & 39.6 \\
& Pyroxenia & 68.4 & 25.2 & 48.4 \\
& Codimi & 82.9 & 31.6 & 61.1 \\
& Moschus & 70.1 & 33.1 & 54.2 \\
& Alombo & 69.6 & 39.8 & 58.9 \\
III & Celive & 71.4 & 38.0 & 59.8 \\
& Pyroxenia & 43.9 & 17.6 & 60.8 \\
& Codimi & 44.0 & 18.6 & 24.6 \\
& Moschus & 56.0 & 20.2 & 33.6 \\
& Alombo & 57.5 & 17.5 & 39.8 \\
Mean & Celive & 56.6 & 24.2 & 42.4 \\
& & 61.3 & 28.1 & 43.7 \\
\hline
\end{tabular}

$\mathrm{LSD}_{0.05}$ for years -3.0 ; interaction: years $\times$ harvest times $\times$ cultivars -13.5 . 


\section{CONCLUSIONS}

1. Weather conditions in the years of the experiment significantly differentiated the content of sugars in maize plants.

2. The highest content of dry matter was characteristic of green forage of all plants of all maize cultivars harvested in the stage of waxy ripeness in 2011, the highest content of starch - also of green forage of all maize cultivars harvested in the same development phase, but in 2010, and of soluble sugars and reducing sugars - also green forage of all maize cultivars harvested on harvest date III, but in 2009 .

3. Green forage of maize cultivars Codimi, Pyroxenia and Alombo harvested in the stage of waxy ripeness in 2010, a year with the highest precipitation total, was characterised by the most favourable chemical composition.

Conflict of interest: The Authors does not declare conflict of interest.

\section{REFERENCES}

Farre I., Faci J.M., 2006. Comparative response of maize (Zea mays L.) and sorghum (Sorghum bicolor L. Moench) to deficit irrigation in a Mediterranean environment. Agric. Water Manag., 8(3), 135-143, https://doi.org/10.1016/j.agwat.2005.11.001

Filya I. 2004. Nutritive value and aerobic stability of whole crop maize silage harvested at four stages of maturity. Anim. Feed Sci. Tech., 116, 141-150, https://doi.org/10.1016/j.anifeedsci.2004.06.003

Hertmann A., Prestert T., Gedger H., 2000. Bestimmung des optimalen Erntezcipunktes von Silomaissorten mit langsamer "Zum Futterwet von Maiz" (Eds. P. Lebzin, F.J. Schwarz, J. Rath). 86-93.

Hopkins A., 2003. Potential impacts of climate change for grassland: farming industry perceptions, adaptations and mitigation options. Grass. Sci. in Eur., 8, 483-486.

Lynch J.P., O'Kiely P., Doyle E.M., 2012. Yield, quality and ensilage characteristics of whole-crop maize and of the cob and stover components: harvest date and hybrid effect. Grass Forage Sci., 67(4), 472-487, https://doi.org/10.1111/j.1365-2494.2012.00868.x

Magalhäes A., Rolim M., Duarte A., Pedrosa E., Silva E., 2015. Chemical attributes of soil and dry mass accumulation of maize fertilized with cassava wastewater. Engen. Agric., 35(3), 458-469. https://doi.org/10.1590/1809-4430-Eng.Agric.v35n3p458-469/2015

Michalski T., Kruczyńska H., Kowalik I., 2002. Yields and quality of ensilaging maize depending on the cultivar and mowing height at harvest. Acta Sci. Pol. Agric., 1(2), 83-92.

Nawab A., Anjum M.M., 2017. Effect of Different Nitrogen Rates on Growth, Yield and Quality of Maize. Mid. East Jour. Agric. Res., 6(1), 107-112.

Podkówka L., Podkówka Z., Piwczyński D., Buko M., 2015. The effect of cultivar earliness on the chemical composition and digestibility of maize grain (in Polish). Rocz. Nauk Zoot., 42(2), 155-169.

Ptaszyńska G., Sulewska H., 2008. Variation of yields of maize hybrids of various earliness in the climatic conditions of the region of Wielkopolska (in Polish). Acta Sci. Pol. Agric., 7(3), 93-103.

Schittenhelm S., 2008. Chemical composition and methane yield of maize hybrids with contrasting maturity. Eur. Jour. Agron., 29(2-3), 72-78, https://doi.org/10.1016/j.eja.2008.04.001. 
Sowiński J., Liszka-Podkowa A., 2008. Levels and quality of yields of fresh and dry matter of maize (Zea mays L.) and sugar sorghum (Sorgum bicolor (L.) Moench) on a light soil in relation to nitrogen dose (in Polish). Acta Sci. Pol., Agric., 7(4), 105-115.

Stejskalova M., Hejcmanova P., Hejcman M., 2013. Forage value of leaf fodder from main European broad-leaved woody species. The role of grassland in a green future. Grassl. Sci. Europe. 18, 85-87.

Strzetelski A., Jurkiewicz A., Strzetelski J., 2001. Maize silage in cagttle feeding (in Polish). Biul. Inf. Inst. Zoot., 39(1), 49-62.

Sulewska H., 2001. Yielding and nutritive value of maize harvested for green matter in relation to certain cultivation technology factors (in Polish). Rocz. AR Poznań. Rozp. nauk., 315.

Sulewska H., Adamczyk J., Rejek D., 2011. Estimation of yields of new fodder maize hybrids (Zea Mays L.) from Hodowla Smolice (in Polish). Nauka Przy. Tech., 5, 1, 1-11.

Swanckaert J., Pannecoucque J., Van Waes J., Cauwer B., Latre J., Haesaert G., Reheul D., 2016. Harvest date does not influence variety ranking in Belgian forage maize variety trials. Jour. Agric. Sci., 154(6), 1040-1050, https://doi.org/10.1017/S0021859615000994

Szempliński W., Bogucka B., Wróbel E., 2009. Ensilage suitability of maize hybrids with varied earliness in the conditions of the Warmińsko-Mazurskie Province (in Polish). Acta Sci. Pol. Agric., $8(1), 57-68$.

Tolera A., Berg T., Sundstøl F., 1999. The effect of variety on maize grain and crop residue yield and nutritive value of the stover. Anim. Feed Sci. Technol., 79(3), 165-177, https://doi.org/10.1016/ S0377-8401(99)00025-5

Tolera A., Sundstøl F., Said A.N., 1998. The effect of stage of maturity on yield and quality of maize grain and stover. Anim. Feed Sci. Technol., 75(2), 157-168, https://doi.org/10.1016/ S0377-8401(98)00192-8

Yuxiang Ch., Jing Ch., Daowei Z., 2007. Effect of harvest date on shearing force of maize stems. In Liv. Sci., 111(1), 33-44, https://doi.org/10.1016/j.livsci.2006.11.013 